\title{
Erratum to: Identification of some main Streptococcus iniae associated proteins: relationship
}

\author{
Fatima El Aamri ${ }^{1}$. José Ángel Guillén ${ }^{2}$ Daniel Padilla ${ }^{3}$. Jimena Bravo ${ }^{4}$. \\ Belinda Vega ${ }^{4} \cdot$ Félix Acosta ${ }^{4}$. Fernando Real ${ }^{3}$
}

Published online: 22 March 2017

(C) Springer Science+Business Media Dordrecht 2017

\section{Erratum to: Vet Res Commun}

DOI 10.1007/s11259-017-9675-Z

The authorship of this article was changed after publication upon request of the authors. The corrected authorship is presented here.

Félix Acosta and Fernando Real contributed equally to this work

The online version of the original article can be found at http://dx. doi.org/10.1007/s11259-017-9675-z

Daniel Padilla

daniel.padilla@ulpgc.es

1 Institut National de Recherche Halieutique (INRH), M'diq, Casablanca, Morocco

2 Unidad Asociada de Biomedicina IIBM CSIC, University of Las Palmas de Gran Canaria, Las Palmas, Spain

3 University Institute of Animal Health, University of Las Palmas de Gran Canaria, 35413 Arucas, Spain

4 Grupo de Investigación en Acuicultura (GIA), Instituto EcoAqua, Universidad de Las Palmas de Gran Canaria, PCTM, Las

Palmas, Spain 